\title{
RESULTS OF RADIATION PROTECTION PROGRAMMES ON MAMMOGRAPHY
}

\author{
N. Machado ${ }^{1, *}$, P. Carvoeiras ${ }^{2}$ and N. Teixeira ${ }^{1}$ \\ ${ }^{1}$ Escola Superior Tecnologias da Saúde de Lisboa, Av. D. João II, Lote 4.69.01, \\ 1990-096 Lisboa, Portugal \\ ${ }^{2}$ Medical Consult, Lda Av. Columbano Bordalo Pinheiro, 85, $6^{\circ}$ F, 1070-061 Lisboa, Portugal
}

\begin{abstract}
In this paper, we present the results of mammography quality control tests related to the work with Portuguese mammography equipment, either in conventional or in digital mammography computed radiography, showing the main differences in the tested equipments. Quality control in mammography is a very special area of quality control in radiology, which demands relatively high knowledge on physics. Digital imaging is changing the standards of the radiographic imaging. Regarding mammography, this is yet a controversial issue owing to some limitations of the digital detectors, like the resolution for instance. A complete set of results regarding radiation protection of the patients submitted to mammography diagnosis is presented. A discussion of the quality image parameters and its interpretation in conventional and digital mammography is presented. In conclusion, we present a sample of results that can be considered as characteristics of mammography equipment in Portugal.
\end{abstract}

\section{INTRODUCTION}

Early detection is one of the main criteria for the successful treatment of all oncological diseases, including breast cancer. Breast cancer screening programmes depend on X-ray mammography because it is a low-cost and low-dose procedure that has the sensitivity to detect early stage breast cancers.

Mammographic features characteristic of breast cancer are masses, particularly ones with irregular margins, clusters of microcalcifications, architectural distortions of breast structures, and asymmetry between corresponding regions of images of left and right breast ${ }^{(1,2)}$.

For the early stage detection of microcalcifications, an important requirement is that the equipment for mammography should have a resolution capable of detecting microcalcifications as small as $100 \mu \mathrm{m}$ in $\operatorname{size}^{(3)}$, which requires a system with a high-spatial frequency. In some countries $12 \mathrm{lp} \mathrm{mm}^{-1}$ is legally required (e.g. Portugal ${ }^{(4)}$ ). The latest generation of computed radiography (CR) detectors have a pixel size of $50 \mu \mathrm{m}$, which corresponds to a system of spatial frequencies of $101 \mathrm{p} \mathrm{mm}^{-1}$, due to Nyquist theorem $^{(1)}$ (Figure 1).

The resolution requirement in mammography is very demanding not only for the image acquisition system but also for the X-ray tube. For instance, the focal spot of the mammography machines is equal to, or smaller than, $0.3 \mathrm{~mm}$ and sometimes are as small as $0.10 \mathrm{~mm}$. The screen-film mammography depends on a single emulsion film with a single phosphor screen.

*Corresponding author: nuno.machado@estesl.pt

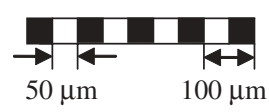

Figure 1. Relationship between spatial frequency of the image $\left(10 \mathrm{lp} \mathrm{mm} \mathrm{mm}^{-1}\right.$, the inverse of the space period $100 \mu \mathrm{m})$ and the detector pixel size $(50 \mu \mathrm{m})$.

There is some mammography equipment (e.g. GE Senographe DMR + ) that does a 'preview' of the $\mathrm{X}$-ray exposure. This type of equipment measures the attenuation of the beam in the local area of the automatic exposure control (AEC) detector with a very short and small dose exposure, chosing the $\mathrm{X}$-ray energy, dose and anode-filter combination. This 'preview' is a very useful tool from the point of view of radiological protection. For example, if there is some high-attenuation structure (e.g. an artificial implant) located above the AEC detector this 'preview' will avoid an unnecessary exposure to the health tissues that would not result in an acceptable diagnostic image.

In the change from the screen-film system to the CR system there is not, normally, any kind of optimisation of the image, because the installer of the $\mathrm{CR}$ system relies on the previous parameters for the screen-film system. This procedure is good enough for the image quality, but in terms of radiological protection it results in a non-optimised image. This can even result in a superior dose delivered to the patient, owing to the higher attenuation of the CR medium compared with that of the screen-film. In radiology departments with consultancy in medical physics, the dose delivered to the patients should be optimised by appropriate measurements, mainly on the signal-to-noise ratio vs. quality of the image. 


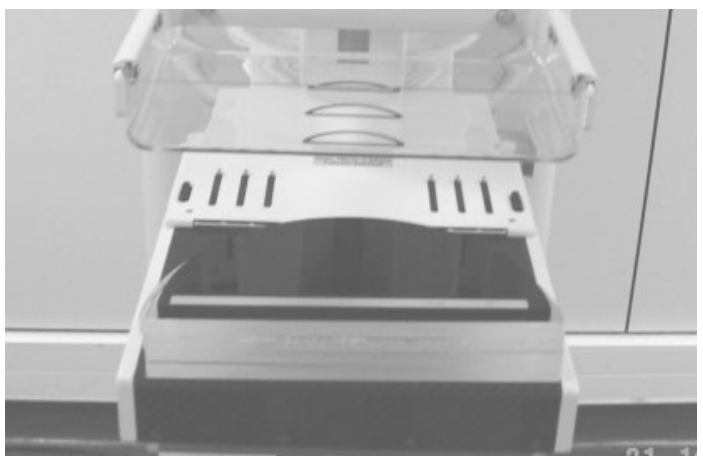

Figure 2. Photographs of a Leeds Test Object on top of acrylic, with a total of $4 \mathrm{~cm}$ thickness of acrylic, approximately.

\section{MATERIALS AND METHODS}

The mammography equipments, such as the GE Senographe DMR+, the Siemens Mammomat 1000, the Siemens Mammomat 3000 Nova and a Phillips Mammodiagnost UC, were used.

The screen-film systems with the combinations of Agfa-Kodak, Kodak-Kodak and Fuji-Fuji were used. The CR system used was Fuji system, with the scanner FCR-5000MA plus.

The measurements of the image quality parameters were performed with the Leeds Test Object ${ }^{(5)}$ TORMAX and TORMAM, with a total of $4 \mathrm{~cm}$ of acrylic (Figure 2). These test objects have groups of filaments, microcalcifications simulations, lowcontrast details circles, resolution test patterns and other types of structures, through which it is possible to measure the main parameters of the image.

The radiographies were acquired with $28 \mathrm{kV}$ AEC using molybdenum anode and filter.

The dose measurements were made using Unfors Mult-o-meter $508^{(6)}$. For the average glandular dose measurements, the detectors were placed on top of acrylic, with $4 \mathrm{~cm}$ thickness, (Figure 3 ) as described previously $^{(7)}$.

\section{RESULTS}

Table 1 presents the image quality results. The maximum spatial frequency presented is the maximum theoretical value as calculated for $50 \mu \mathrm{m}$

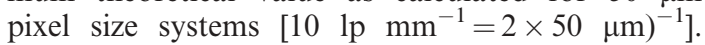
TCDD is the acronym for threshold-contrastdetail-detectability, related to the contrast resolution.

Table 2 presents the average dose measurements results with several screen-film arrangements $(28 \mathrm{kV}$ with AEC).

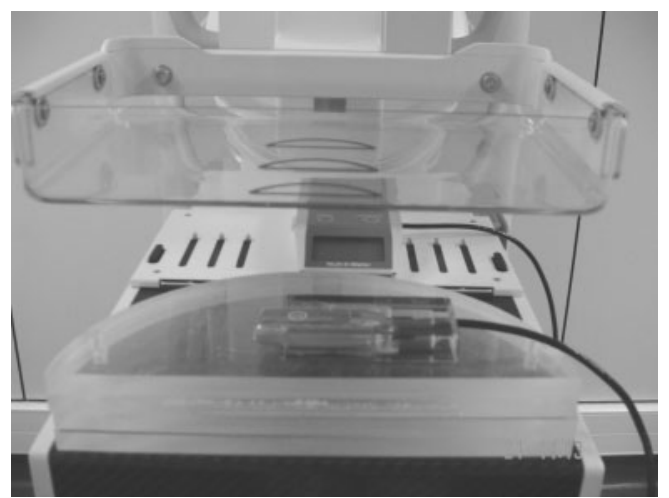

Figure 3. The dose measurements were made at the entrance surface of $4 \mathrm{~cm}$ acrylic.

Table 1. Image quality results.

\begin{tabular}{|c|c|c|}
\hline Parameter & $\mathrm{CR}$ & Screen-film \\
\hline $\begin{array}{l}\text { Maximum spatial } \\
\text { frequency }\end{array}$ & $10 \mathrm{lp} \mathrm{mm}^{-1(\mathrm{a})}$ & $16.6-20 \mathrm{lp} \mathrm{mm}^{-1}$ \\
\hline $\begin{array}{l}\text { TCDD } 6 \mathrm{~mm} \\
\text { detail }(\%)\end{array}$ & 0.85 & $1.0-1.5$ \\
\hline $\begin{array}{l}\text { TCDD } 0.5 \mathrm{~mm} \\
\text { detail }(\%)\end{array}$ & 2.0 & $2.8-3.9$ \\
\hline $\begin{array}{l}\text { TCDD } 0.25 \mathrm{~mm} \\
\text { detail }(\%)\end{array}$ & 5.6 & $5.6-11$ \\
\hline $\begin{array}{l}\text { Diameter of the } \\
\text { minimum visible } \\
\text { filament (mm) }\end{array}$ & 0.225 & $0.225-0.25$ \\
\hline
\end{tabular}

(a) This value corresponds to the maximum theoretical value, not a measured value

Table 2. Average results for dose measurements $(28 \mathrm{kV}$ with AEC) with several screen-film arrangements and a $4 \mathrm{~cm}$ acrylic phantom.

\begin{tabular}{|c|c|c|c|c|}
\hline \multirow[t]{2}{*}{ Parameter } & \multicolumn{3}{|c|}{ Average value } & \multirow[t]{2}{*}{ Tolerance $^{(8)}$} \\
\hline & $\begin{array}{l}\text { Fuji- } \\
\text { Fuji }\end{array}$ & $\begin{array}{l}\text { Kodak } \\
\text { Min R2- } \\
\text { Kodak }\end{array}$ & $\begin{array}{l}\text { Agfa- } \\
\text { kodak }\end{array}$ & \\
\hline $\begin{array}{l}\text { Average kerma } \\
\text { on entrance } \\
\text { surface (mGy) }\end{array}$ & 7.02 & 3.90 & 5.30 & $<12.0$ \\
\hline $\begin{array}{l}\text { Average } \\
\text { exposure time (s) }\end{array}$ & 0.62 & 0.36 & 0.70 & $<2.00$ \\
\hline $\begin{array}{l}\text { Average } \\
\text { glandular dose } \\
\text { per exam (mGy) }\end{array}$ & 1.4 & 0.78 & 1.4 & $<2.0$ \\
\hline
\end{tabular}

\section{CONCLUSIONS}

Normally the appearance of digital images is better than the screen film images, owing to its enhanced dynamic range, or grey scale. This 


\section{N. MACHADO ET AL.}

means that the breast structures will appear more clearly in the digital systems than in the conventional ones.

The screen-film spatial frequency is $>161 \mathrm{p} \mathrm{mm} \mathrm{m}^{-1}$, but there is no significant difference in the detection of microcalcifications between this system and the $\mathrm{CR}$ system. This is because of the difficulty in detecting the small structures on the film, while in digital systems the small calcification structures are enhanced and more easily visible.

As expected, the TCDD (contrast resolution) is slightly better in digital systems, compared to the conventional ones. In screen-film systems, the measured values are always between 1.0 and $1.5 \%$. In digital systems, owing to the automatic adjustments on each image after the scanning, the TCDD values are always $<1.0 \%$.

For small details (size of 0.5 and $0.25 \mathrm{~mm}$ ), the visibility threshold is more or less the same in both types of the systems, but the screen-film is unstable and very sensitive to the instability of the developer machine.

\section{REFERENCES}

1. Yaffe, M. J. Digital mammography. In: Handbook of Medical Imaging. Vol. 1, Physics and Psycophysics. Beutel, J., Kundel, H. and Metter, R., Eds. (Yaffe, WA, Spie Press) (2000), ISBN 0-8194-3621-6.

2. Bushberg, J. T., Seibert, J. A., Leidholdt, E. M. and Boone J. M. The Essential Physics of Medical Imaging, second edition (Bushberg, DA, Lippincott Williams and Wilkins) (2002), ISBN 0-6833-0118-7.

3. Farr, R. F. and Allisy-Roberts, P. J. Physics for Medical Imaging (Farr, UK, WB Saunders Company Ltd) (2002), ISBN 0-7020-1770-1.

4. Portuguese legislation Decreto-lei no.180/2002, 8 August. Diário da República no.182 (2002).

5. Available on www.leedstestobjects.com.

6. Available on www.unfors.com.

7. The Institute of Physical Sciences in Medicine. Commissioning and routine testing of mammographic $X$-ray systems. Report no.59 (1989), ISBN 0-904181-58-8.

8. The Institute of Physics and Engineering in Medicine. Recommended standards for the routine perfomance testing of diagnostic X-ray imaging systems. Report no. 77 (York, UK: IPEM) (1998), ISBN 0-90418187-1. 